\title{
Farmers' Preference for Soil and Water Conservation Practices in Nigeria: Analytic Hierarchic Process
} Approach

\author{
Seyi Olalekan Olawuyi \\ University of Fort Hare, Eastern Cape Province, South Africa \\ seyidolapo1704@gmail.com
}

\begin{abstract}
Enhancing agricultural production through sustainable soil/land and water conservation practices are vital to the sustenance of the human race as entrenched in the United Nation's Sustainable Development Goals 2, 12 and 15 respectively. Smallholder farmers are faced with myriads of soil and water-related issues in production which make them vulnerable to land degradation and low productivity. This calls for policies to enhance sustainable food production; hence, the need for this study which highlighted the influencing dynamics governing the preference and use of SWC practices alternatives in Nigeria with particular reference to Osun State. Multi-stage sampling technique was adopted in this study to select the representative sample of 240 respondents. Data collected through primary source include information on selected farmers' socioeconomic attributes, institutional and farm level characteristics as well as the SWC practices prevalent in the study area. The SWC practices highlighted in this study include: Soil Management/Amendment Practices (SAP), Agronomic Practices (AP) and Cultivation Practices (CP). The data collected were analyzed with crosstabulation analysis, AHP technique and the logit regression model. The results from AHP revealed that Agronomic Practices (AP) is the most preferred and used SWC practice option in the study area while marginal effects of the logit regression revealed that age, gender, years of formal education, membership of local level institutions, access to extension services and frequency of extension visit as well as farmers' perception on the impact of extension visit are significant influencing dynamics governing the rural farmers' preference and use of SWC practices alternatives in the study area. Hence, concerted efforts should be geared towards developing pro-farmers policies in line with these influencing dynamics.
\end{abstract}

Keywords: Soil and water conservation, Preference, MCDM-AHP, Logit, Nigeria

\section{Introduction}

Land degradation according to James and Ngala, (2015a) is a critical problem mostly caused by human activities. It is a major consequence of soil and water-related issue in agricultural production and partly that of climate change problem because there is groundwater loss due to increased temperature which often results in soil productivity decline. It usually occurs as a result of the interactions of various factors such as population pressure, obsolete, inefficient and traditional farming practices by humans. The traditional farming systems employed by most smallholder farmers who are also resourced poor have led to dwindling and reduced production output which in turn manifests in low revenue accrue and by extension vicious cycle of poverty. This ugly scenario has a negative effect on the availability and distribution of food crops especially the arable crops across the nation and especially the study area. However, past studies (for instance; Ezeaku, 2012; Dimelu, Ogboona and Enwelu, 2013; Babalola and Olayemi, 2013) have stressed on the significance of modern agricultural practices and the need for a transition from farmers' obsolete farming techniques to improved modern practices such as SWC practices.

It was further noted by these studies that improved farming practices can significantly have multiplier effects on the production output; which implies that, its capacity to improve the welfare of the populace cannot be underestimated. Therefore, against this background, this study examined the influencing dynamics driving the use of modern SWC practices by reflecting on the smallholder farmers' preference and use of SWC practices alternatives. It is important to note that, efficient use of these modern farming practices is vital to the sustenance of the human race as entrenched in the United Nation's Sustainable Development Goals 2, 12 and 15 respectively. And, nothing is more basic to the long-term survival of the human race than the availability of fertile soils to maintain plant and animal population. Yet, soils have been mined by erosion, constant cultivation and extraction of available nutrients (James and Ngala, 2015a). Therefore, because of this development, the policy calls for a sustainable agricultural development and production system such as Soil and Water Conservation (SWC) Practices came to the forefront. Soil and water conservation practices are practices or multi-practices that aim at achieving the following set of objectives. 
Covering of soil surface with crop residues to enhance water percolation and/or infiltration rate, reduces topsoil runoff and achieving enhanced soil fertility for improved agricultural production output. And, such practices according to Adimassu et al. (2013) include but not limited to: terracing, tree planting, agroforestry, cover cropping, sole cropping, mixed cropping, contour vegetation strip and zero or minimum tillage. These sets of practices could either be used singly or in combination; in fact, most farmers use a combination of these practices to achieve an optimum productivity output. In the same vein, Ezeaku, (2012) strongly emphasized the need for sustainable soil and water management strategies in farming activities. The author also stressed on the necessity to guard against the washing away (being eroded) of the topsoil from the earth's surface or becoming altered chemically as a result of several factors associated with overutilization of soil, salinization and/or acidification, or chemical contamination of soil. All these are in line with the earlier school of thoughts discussed. Ezeaku, (2012) further noted that, good and efficient combination soil and water management techniques or practices will guard against soil degradation and depletion as a result of the natural occurrence, human activities and other human-induced factors. In the opinion of Dumaski et al. (2006) as well as Smith and Smithers, (2006), the soil and groundwater management practices efforts "offer and promote minimum disturbance of the soil by tillage (minimum tillage) as well as balance application of chemical inputs which are required to improve soil quality for healthy crop production. In essence, effective soil and groundwater conservation practices can potentially boost soil productivity and groundwater loss, reduce long-term dependency on external inputs which often times led to increased cost of production and enhance environmental management as well as reduce the emission of greenhouse gases borne out of human activities such as burning". All these can ultimately improve agricultural productivity and food security with minimum costs given considerations to the available cultivable land resources in Africa and sub-Saharan Africa in particular.

According to James and Ngala, (2015a), of the total landed area of approximately 2,976 million ha in Africa, two-third of this quoted figure is associated with various production limitations such as low fertility, saline and poorly drained soils and soil acidity. This situation has earlier been emphasized and affirmed by Mbagwu, (2003) who stated that poor and inappropriate soil and water management practices are the main cause of physical, chemical and biological degradation of most cultivated land in Africa which is manifested through an obvious yields decline, decreased vegetation covers, soil salinity, low soil fertility, loss of groundwater as well as increasing rate of soil erosion. These are clear indications of soil degradation and desertification with attendant negative consequences on food security and zero hunger. Therefore, soil depletion and erosion pose a serious threat to the agricultural development of nations which is a call to action point for local, state, national and regional economic development; most especially in an agrarian-based economy such as Nigeria where the majority are smallholder rural farmers. In response to this issue, mitigation pathways are the major talking points among agricultural policymakers and experts in sub-Saharan Africa (SSA) and Nigeria in particular (Iheke and Onyenorah, 2012). In Nigeria, over $80 \%$ of the farmland areas are being ravaged by erosion. This situation exposes farmland to degradation because of the run-off.

An estimated mean annual loss of about 25 million tons of crop productive capacity according to Olatunji, (2003) as cited in James and Ngala, (2015b) has been attributed to land degradation with attendant consequences of low yield, famine, low standard of living, reduction in availability of fuelwood, food insecurity, poverty and ultimately rural-urban migration. On the other hand, Salako and Tian, (2003) as cited in James and Ngala, (2015b) noted that farms which adopt soil and water conservation practices did have increased yields compared to the farms which did not, even as they operate in the same agro-ecological zone or region. Therefore, soil productivity maintenance in the short and long run is an important crux of conservation of both soil and groundwater to boost food crop production. Recently, Dimelu et al. (2013) stressed that, land degradation issue is a significant threat to the achievement of a sustainable food production system. This is also threatening the realization of United Nations' Sustainable Development Goal2as well as the welfare of the smallholder farmers considering their traditional methods of farming. This issue as emphasized by Dimelu et al. (2013) is a major impediment to: the sustained agricultural development of nations-especially agriculture-dependent ones, achievement of zero hunger, better rural farming households' welfare and poverty reduction in the world, SSA and Nigeria in particular. Apparently, rural farmers are known to use several traditional practices such as simple agronomic practices, age-long soil amendments management practices as well as the obsolete mechanical methods of soil management. Nonetheless, the application of these techniques has just been useful in keeping the pace of production, at 
least on a considerable subsistence level, but not without its attendant consequences such as land degradation and productivity decline after a certain limit.

However, several efforts have been put forward and implemented to reverse this ugly situation and trend of land degradation, but available documented evidence of public interventions on soil and groundwater conservation in Nigeria and other developing countries revealed a poor performance (for instance, Babalola and Olayemi, 2013; Dimelu et al. 2013; James and Ngala, 2015a). The reasons adjudged for this poor impacts could be attributed to the nature of conservation practices involved (Babalola and Olayemi, 2013; AnandeKur, 1986), socio-economic and demographics of the farmers who are the users of these practices, among other explainable and unexplainable factors (Jansen et al. 2006; Bravo-Ureta, et al. 2006). It thus becomes imperative to pay proper attention to this topical issue bothering on food and nutrition security as well as the welfare condition of the populace. In addition, based on the submission of Babalola and Olayemi, (2013), concerns on the need to meet the food demand with attendant myriads of socio-cultural problems and political instability as well as unstable economic situation are other serious challenges facing Nigerian rural farmers. Thus, appropriate and genuine interventions devoid of political interference can certainly affect food and nutrition security positively among nations. Similarly, combating land degradation through appropriate choice and preference of soil and water management practices by farmers has become an urgent priority in the global efforts to ensure zero hunger and food security for the ever-bourgeoning population in Nigeria.

Most importantly, the appropriate measure and evaluation tool on choice and preference for SWC practices by farmers need serious attention. Recently, multi-criteria analysis (MCA) technique otherwise known as Multi-Criteria Decision Making (MCDM) technique has been identified and emerged as an alternative and relatively comprehensive evaluation tool for choice and preference based survey; this was followed and extended to this study focusing on SWC practices preferences among smallholder farmers which of course include non-economic criteria. From the reviewed literature so far, there is no known study which have been conducted on the preference and choice of SWC practices and which clearly and explicitly considers and integrates farmers' economic needs and environmental objectives at a local level in Nigeria using MultiCriteria Decision Making (MCDM) approach. Based on the aforementioned, this study investigated the influencing dynamics on farmers' preference for soil and water conservation practices in Nigeria with particular reference to Osun State, South-Western Nigeria; the choice of the study area is governed by the prevalent farming activities in this region especially among rural smallholder farmers.

\section{Materials and Methods}

The Study Area: The study was conducted in Osun State, Nigeria; located in the South-western part of Nigeria. The area is agrarian in nature, which is responsible for the prevalent farming and farming related activities; though mostly dominated by smallholder farmers. More so, other livelihood activities available in this area include but not limited to food processing, marketing, civil service and trading. There also abounds moderate level of social capital among the inhabitants of this area under study which informs the observed interactions and homogeneity in culture, values and norms among the residents.

Sampling Units and Procedure: The Agricultural Development Program (ADP) of Osun state is structured into 3 strata; these are: Osogbo, Iwo and Ife-Ijesha zones. Multistage sampling technique was used to select the240 respondents used for this study. A purposive selection of Iwo and Ife-Ijesha ADP zones was carried out in the first stage because of the prevalent agricultural activities in these zones. Thereafter, random and proportionate to size sampling techniques were simultaneous used to select the representative sample used for this study. The reason for this approach is to give individual farmers equal opportunity of being selected and to account for the variation in the respective population across the villages selected and used for this study.

\section{The Proportionality Factor is given as:}

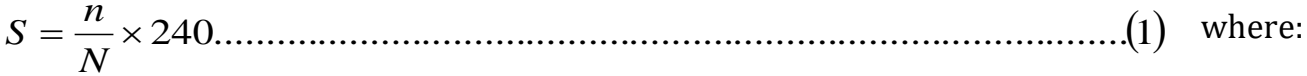

$$
\begin{aligned}
& \mathrm{S}=\text { sampled respondents from each of the selected villages, }
\end{aligned}
$$


$\mathrm{n}=$ population of registered farming households in each of the selected villages,

$\mathrm{N}=$ total population of registered farming households in all the 8 villages chosen,

$240=$ total number of respondents sampled in the study area.

Data Collection and Analytical Techniques: The study made use of cross-sectional data sourced primarily by administering study objectives-based questionnaires to the farmers in a scheduled interview process due to the perceived low literacy level of the respondents in the study area. Cross-tabulation analysis and mean values were used to describe the farmers and farm-based characteristics in relation to preference for soil and water conservation practices. Also, using Focus Group Discussion (FGD) with the farmers, Multi-Criteria Decision Making (MCDM) (using Analytic Hierarchic Process (AHP) technique as earlier applied by Saaty, (1987) and Adimassu et al. (2013) was employed to determine the optimal farmers' choice/preference for soil and water management practices among several other alternatives. The choice of this technique becomes useful to find out which of the exploratory scenarios with respect to choice and preference for soil and groundwater conservation practices best matches the farmers' (who are decision makers) expectations and sets of options/alternatives; the caveats needed to satisfy with respect to this methodology suggest that decision makers (farmers) need to agree or reach a consensus on a weighted set of criteria with which to judge the performance of the soil and water conservation practices chosen. Thereafter, the logit regression model was used to isolate the influencing dynamics governing the rural farmers' preference for each of the dominant soil and water conservation practices alternatives. Results obtained were further subjected to diagnostic test and post-estimation analysis to ascertain the goodness of fit and reliability of the model with the use of STATA 13 software.

Approach to Multi-Criteria Decision Making Analysis (Analytic Hierarchic Process Technique): This study benefited immensely from the guidelines provided in the works of Toda et al. (1981); Saaty, (1987); Mendoza and Martins, (2006); Adimassu et al. (2013); Babalola and Olayemi, (2013) and Chaudhuri, (2014). In line with the caveats governing the use of MCDM approach (AHP technique) and following the stepwise procedure as explained and highlighted in the reviewed literature, MCA on decision making among several alternatives using Analytic Hierarchic Process was adopted and used to carefully mirror farmers' preference and choice use decision of soil and water conservation practices. Multi-Criteria Decision Making (MCDM) or MCA technique employed to assess the preferences of soil and water management practices is a "pragmatic evaluation framework that ranks the performances of decision options against multiple objectives/criteria (Hajkowicz and Collins, 2007; Hajkowicz, 2008). Typically, the criteria were weighted using pair-wise ranking by decision makers (farmers) to reflect their relative importance. Criteria are attributes or indicators used to measure performance against decision makers' objectives. MCDM or MCA is a systematic way of making choices according to criteria and available options (Hajkowicz, 2008; Herva and Roca, 2013)".

This approach does not rely on monetary values and it offers a great potential to address the shortcomings of other evaluation methods (for instance, cost-benefit analysis). This method has been widely applied by several authors to evaluate natural resource management technologies and events that have to do with choice and preference (see Ananda and Herath, 2009; Chaudhuri, 2014). According to Adimassu et al. (2013), the following are the major AHP techniques and stepwise procedures involved:

- $\quad$ Establishing the decision context/determination of objectives

- Identifying options/alternatives

- Identifying criteria

- Determining the effects of alternatives

- Standardizing the effects of alternatives

- $\quad$ Ranking the criteria

- $\quad$ Aggregating results and ranking

Following the above stepwise procedures, this study evaluated the preference and choice of SWC practices by the farmers using the AHP approach. And, from a large set of probable choices and based on the overall joint preferences of the farmers with respect to the choice and use of SWC practices, a small set of suitable choices were agreed on. Hence, from the FGD session, the followings represent the agreed short-listed choices: soil management/amendment practices, agronomic practices as well as cultivation practices. The reason for this is that, it is important to quickly form the first set of preferences and make a short-list on the basis of 
evaluation of these short-listed choices informally. This thus helps to focus on detailed analysis and evaluation based on preferences covering a small number of choices. Also, using inventive principle rushing through technique, a criteria analysis was done and the following three short-listed criteria were agreed on: maintenance criteria (soil fertility), technical criteria (reduction in soil loss and soil moisture improvement), and economic criteria (crop yield increase and low labor requirements).

Apparently, the choice and use of SWC practices are reliant on the objectives set to achieve as highlighted in the shortlisting criteria. According to Chaudhuri, (2014), the caveats needed to fulfil with respect to AHP technique stipulate the use of a limited number of criteria and that the short-listed criteria are fairly mutually exclusive of each other and also be comprehensively exhaustive. It is worthy of note that this second requirement is of paramount importance in any kind of multi-criteria decision making analysis to avoid creating an entangled situation. Then, the inter-criteria judgment matrix was constructed by doing a detailed analysis of evaluation criteria exhaustively together with short-listing of favorable choices. And, between the three criteria, the farmers were asked to make a judgment on which is more important and how much more important is the criteria one by one; and this was recorded by putting judgmental values $(1,2$ and 3 corresponding to "equally important", "somewhat more important" and "extremely more important" in that order) to the judgment matrix (3 by 3 matrix) as shown in Table 3a. This is where the mathematics of assigning numerical values to the agreed judgment on the relative importance of the three criteria comes in. Therefore, the farmers' judgment on: maintenance criteria, technical criteria and economic criteria were scored and ranked based on the order of importance. It is pertinent to note that there exists a high level of social-cohesion viz-a-viz social capital among the sampled smallholder farmers owing to their involvements in local level institutions in the study area.

This also informs the similarities observed in their decision with respect to the choice and use of SWC practices as well as the criteria agreed on during the FGD exercise. The evaluation of the judgment matrix finally produced the inter-criteria importance in the form of a decimal number for each criterion; the total of which must be equal to unity (1). And, the more the value share of a criterion is, the more is its importance while evaluating the choices against all the criteria. This decimal share is thus referred to as the 'inter-criteria weight' (Chaudhuri, 2014). Thereafter, the evaluation of the relative importance of the choices against the criteria was done as shown in the choice versus criteria table (that is, Table $3 \mathrm{~b}$ ) where the farmers were asked to assign judgmental utility values (un-weighted) to each choice against each criterion with a caution that the allotted decimal number values to each 'choice-criterion cell' for the three choices against a criterion must also sum up to unity (1) as specified by (Chaudhuri, 2014). And, the final step involved multiplying the un-weighted utility values by the corresponding criteria weights and total up to arrive at the final weighted utility values for the choices. Hence, the choice with the highest weighted total utility value is the most preferred and used choice of SWC practices by the farmers in the study area.

Logit Regression Model: The choice of the logit model is guided by the fact that the response variable(s) are discrete and/or dummy. Hence, where the response variable is dichotomous, the two commonly used models are logit and probit regression models. In line with the submission of Amemiya, (1981), the use choice between these two models is at times confusing as a result of the statistical similarity between them. However, the logit model is computationally easier and adopted for this study.

Following Gujarati (1988), the model is specified as follows:

$L_{n}\left(P_{i} /\left(1-P_{i}\right)=\beta_{0}+\beta_{1} X_{1}+\beta_{2} X_{2} \ldots \ldots \ldots \ldots \ldots \ldots \ldots+\beta_{6} X_{6}+\varepsilon_{i} \quad\right.$ where:

$\mathrm{L}_{\mathrm{n}}=$ natural logarithm

$\mathrm{P}_{\mathrm{i}}=$ probability of farmer's preference or choice for different SWC practices

$1-\mathrm{P}_{\mathrm{i}}=$ probability of not using SWC; $\beta_{0}=$ intercept; $ß i(1,2,3 \ldots \ldots \ldots . . \mathrm{n})=$ regression explanatory variables, and $\varepsilon_{\mathrm{i}}$ $=$ random error term.

The dependent variable is the natural logarithm of the probability of a farmer using particular SWC practices divided by the probability of not using it.

The followings are various SWC practices examined in this study:

- Soil Management/Amendment Practices (SAP) which involves the use of any: compost and farm/green manure - organic and inorganic manure. 
- Agronomic Practices (AP) which involves the use of any: mixed cropping, mulching, planting of the cover crop, crop rotation and agroforestry.

- Cultivation Practices (CP) which involves the use of any: minimum/zero tillage and land fallow.

According to Babalola and Olayemi, (2013) as well as Olawuyi and Balogun, (2017), the following variables have been hypothesized to influence adoption - preference, choice and use of SWC practices either positively or negatively based on a-priori expectations:

$\mathrm{X}_{1}=$ age of farmers (years)

$\mathrm{X}_{2}=$ gender of farmers (male $=1,0$, Otherwise)

$\mathrm{X}_{3}=$ years of formal education (years)

$\mathrm{X}_{4}=$ household size (actual number)

$\mathrm{X}_{5}=$ farm size under cultivation (ha/number of plots)

$\mathrm{X}_{6}=$ membership of local level institutions, for instance, farmers' cooperative (yes $=1,0$, Otherwise)

$\mathrm{X}_{7}=$ access to extension services/education by the farmers, (yes $=1,0$, Otherwise)

$\mathrm{X}_{8}=$ frequency of extension visit (actual number of visit)

$\mathrm{X}_{9}=$ perceived impact of extension visit (good $=1$, poor $=0$ ).

$\mathrm{X}_{10}=$ mode of land acquisition (inheritance $=1,0$, Otherwise)

\section{Results and Discussion}

This section presents the summary statistics of the respondents' socioeconomic characteristics. The crosstabulation analysis of the selected respondents' socio-economic characteristics and the preference for SWC practices alternatives and the results of MCDM analysis as well as the dynamics governing farmers' preferences for SWC practices were also highlighted. Also, post-hoc and reliability tests were carried out to ascertain the goodness of fit as well as the reliability of the fitted model. Table 1 revealed the summary statistics of selected socio-economic attributes of the respondents. The findings revealed that the mean age of respondents in the study area is about 52.06 years while the minimum and maximum ages of the enumerated respondents are 24 and 76 years respectively. The maximum years spent in school was estimated at 18 years with a mean value of approximately 7 years corresponding to primary (elementary) school level of education in Nigeria. Also, the maximum household size is 9 persons with an estimated mean of 62 persons in every 10 households. Then, the findings revealed an average farm size under cultivation of approximately $2 \mathrm{ha}$, which suggests that the respondents are smallholder farmers. Additionally, the estimated frequency of extension visits and years of farmers' farming experience are approximately once in every month and 21.28 years respectively. This suggests that the number of extension contact is very low; this can potentially affect the uptake of modern farming techniques such as SWC practices. Similarly, the findings revealed that the respondents have ample years of experience in farming which is also an added advantage for easy uptake and choice of SWC practices.

Table 1: Summary Statistics of Selected Respondents' Socio-Economic Variables

\begin{tabular}{lllll}
\hline Socio-economic variables & Mean & Standard Dev. & Min & Max \\
\hline Age & 52.06 & 11.42 & 24 & 76 \\
Years spent in School & 6.73 & 3.78 & 0 & 18 \\
Household size & 6.22 & 1.86 & 2 & 9 \\
Farm size under cultivation & 1.91 & 1.07 & 1 & 6 \\
Frequency of extension visit & 1.39 & 0.87 & 0 & 3 \\
Years of experience in farming & 21.28 & 11.34 & 1 & 50 \\
\hline
\end{tabular}

Source: Data Analysis, 2017

Cross-Tabulation of Socio-Economic Characteristics \& Preferences for SWC Practices: The results as shown in Table 2 at a glance revealed that fairly aged people ranging between 41-50 and 51-60 years of age are involved in farming activities with the identified three preferred SWC practices alternatives in the study area. More so, the majority of the respondents fall within the educational class of having between 1-6 years and 7-12 years of formal education. In the same vein, many of these farmers involved in the identified SWC practices in the study area have their respective household size ranging from 5-8 persons. And, of these three 
preferred SWC practices identified, Agronomic Practices (AP) is the most preferred and used SWC practices option. This finding is consistent with Babalola and Olayemi, (2013); James and Ngala, (2015a).

Table 2: Cross-Tab Analysis of SWC Preferences and Socio-Economic Variables of the Respondents

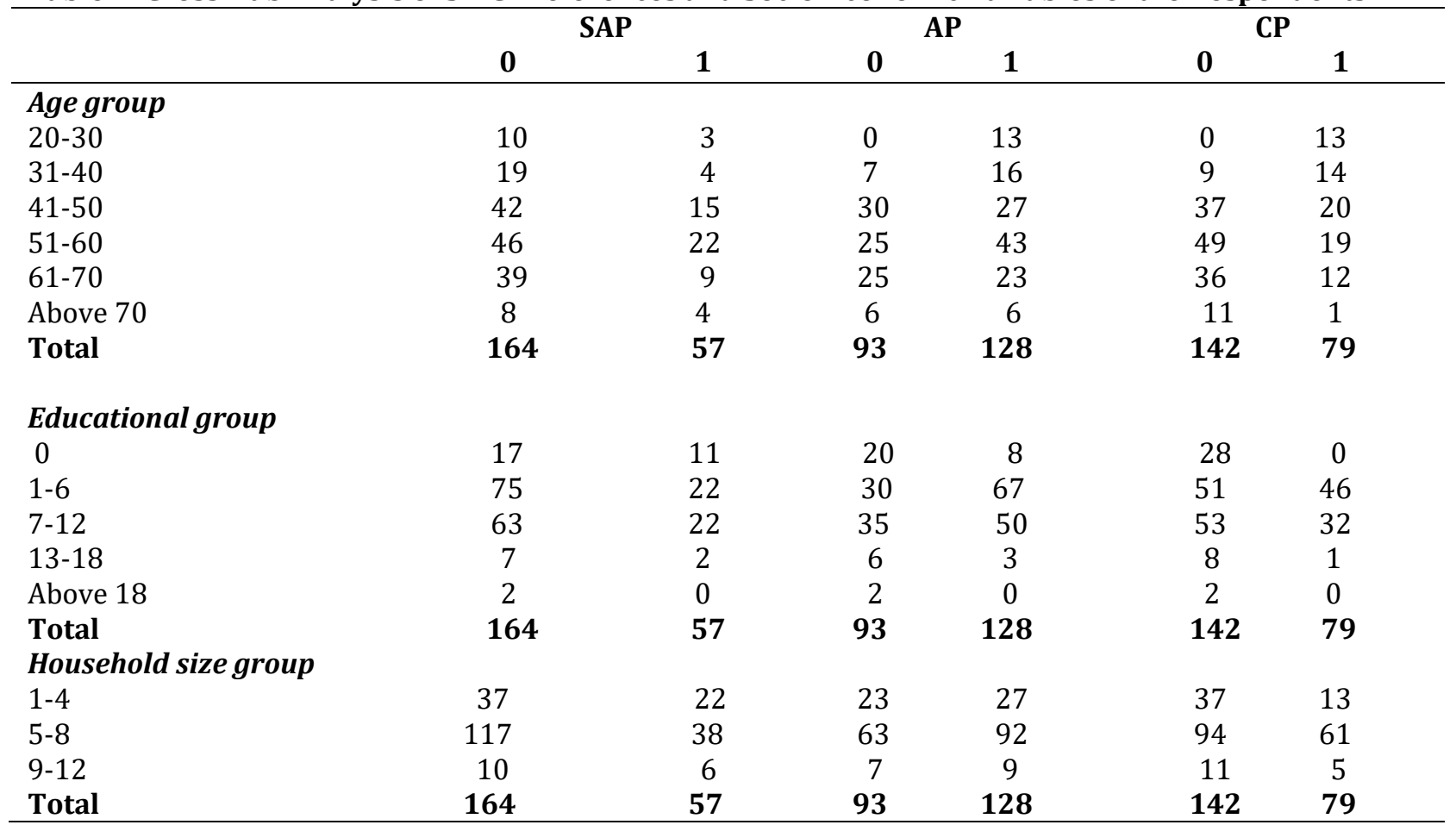

Source: Data Analysis, 2017

Multi-Criteria Decision Making (MCDM) - Analytic Hierarchic Process (AHP) Technique: The results as shown in Tables 3a and 3b revealed the farmers' preference and used a choice of the identified SWC practices alternatives in the study area. And, judging from the results of the MCDM (AHP technique) final step as described earlier, that is, the final weighted utility values for the choices made, it can therefore be logically inferred that the choice with the highest weighted total utility value (Agronomic Practices (AP)) is the most preferred and used SWC practices by the farmers in the study area. This thus corroborates the earlier submission made in Table 2.

Table 3a: Inter-criteria Weights

\begin{tabular}{lccccc}
\hline Criteria & $\begin{array}{c}\text { Soil Maintenance / } \\
\text { Amendment } \\
\text { Criteria (2) }\end{array}$ & $\begin{array}{c}\text { Technical } \\
\text { Criteria } \\
\text { (3) }\end{array}$ & $\begin{array}{c}\text { Economic } \\
\text { Criteria } \\
\text { (1) }\end{array}$ & $\begin{array}{c}\text { Row } \\
\text { Totals }\end{array}$ & $\begin{array}{c}\text { Inter-criteria } \\
\text { Weights / } \\
\text { Relative utility }\end{array}$ \\
\hline $\begin{array}{l}\text { Soil Maintenance / } \\
\text { Amendment Criteria (2) }\end{array}$ & $2 / 2=1$ & $2 / 3=0.67$ & $2 / 1=2$ & 3.67 & 0.33 \\
Technical Criteria (3) & $3 / 2=1.5$ & $3 / 3=1$ & $3 / 1=3$ & 5.5 & 0.5 \\
$\begin{array}{l}\text { Economic Criteria (1) } \\
\text { Grand Total }\end{array}$ & $1 / 2=0.5$ & $1 / 3=0.33$ & $1 / 1=1$ & 1.83 & 0.17 \\
\hline Source Author & & & $\mathbf{1 1}$ & $\mathbf{1}$ \\
\hline
\end{tabular}

Source: Author's computation, 2017 
Table 3b: Choice versus Criteria

\begin{tabular}{|c|c|c|c|c|c|c|c|}
\hline \multirow{2}{*}{$\begin{array}{l}\text { Criteria } \\
\text { Weights }\end{array}$} & \multirow[t]{2}{*}{ Criteria } & \multicolumn{3}{|c|}{ Un-weighted Utility Values } & \multicolumn{3}{|c|}{ Weighted Utility Values } \\
\hline & & SAP & AP & $\mathrm{CP}$ & SAP & AP & $\mathrm{CP}$ \\
\hline 0.33 & $\begin{array}{l}\text { Soil Maintenance / } \\
\text { Amendments Criteria }\end{array}$ & 0.4 & 0.5 & 0.1 & 0.132 & 0.165 & 0.033 \\
\hline 0.5 & Technical Criteria & 0.1 & 0.6 & 0.3 & 0.05 & 0.3 & 0.15 \\
\hline 0.17 & $\begin{array}{c}\text { Economic Criteria } \\
\text { Final Values }\end{array}$ & 0.4 & 0.2 & 0.4 & $\begin{array}{c}0.068 \\
0.25\end{array}$ & $\begin{array}{l}0.034 \\
0.499\end{array}$ & $\begin{array}{l}0.068 \\
0.251\end{array}$ \\
\hline
\end{tabular}

Source: Author's computation, 2017

Factors Influencing the Preference for SWC Practices Alternatives: According to Adimassu et al. (2013), the processes through which farmers develop an attitude, make decisions and order their preferences for SWC practices are sequential, which guide the use or non-usage of particular sets of alternatives. And, based on literature review and a-priori expectations, a number of explanatory variables based on farmers' socioeconomic, institutional, and farm level factors were hypothesized to influence farmers' choice/preference and decision to use a particular set of SWC practices. Therefore, the logit regression model was estimated to isolate these influencing dynamics governing the rural farmers' preference for each of the identified and dominant SWC practices alternatives in the study area. In lieu of this, Table 4 presented the post-hoc/postestimation marginal effects result of the fitted logit regression model for each of the three dominant and preferred SWC practices alternatives so as to ascertain the goodness of fit of the model and to clearly mirror the dynamics governing farmers' preferences for SWC practices alternatives. The results revealed a good fit for the SWC practices model as evident by the significance of the diagnostic statistics; that is, chi-squared and $\log$ likelihood values for each of these practices.

The findings further show that gender has an inverse and significant $(p<0.01)$ relationship with the preference/choice and use of SAP among the smallholder farmers in the study area; this suggests that maleheaded households are less likely to prefer and use SAP. In the same vein, years of formal education and access to extension services negatively and significantly $(p<0.1$ and $p<0.01$ respectively) influenced the preference and use of SAP; this implies that the more educated a farmer is, the less likely will be the decision to prefer and use SAP as a measure against land degradation and soil water issue. This is in contrast with apriori expectations and findings of Babalola and Olayemi, (2013), because higher educational attainment is associated with a higher understanding of the importance and use of SWC practices towards achieving sustainable land management and by extension, increased crop productivity output. Also, it is less likely for farmers to prefer and use of SAP with an increase in institutional support such as access to extension services. This is because there is an observed low contact with extension agents in the study area as reported earlier. Conversely, the frequency of extension visit has a direct and significant $(p<0.01)$ influence on the preference and use of SAP in the study area.

This is expected because there is a high likelihood of using one or more of the SWC practices especially the SAP, with an increase in farmers' contact with government institutional framework (in this case, extension system). Likewise, by extension, the farmers' perception on the impact of government institutional support is significantly positive $(p<0.05)$, which suggests that the farmers perceive government continued support as an important entity to achieving sustainable agricultural production through appropriate SWC practices. Also, the use of CP in the study area according to the findings was influenced by the age of the respondent, gender of the respondents and access to government institutional support (for instance, extension visit). These variables are significant ( $p<0.05 ; p<0.01 ; p<0.05$ respectively) and inversely influence the use of CP in the area under study. This suggests that there is less likelihood with respect to preference and use of CP as an SWC practice with an increase in age of the respondent; though, the result is viewed with mixed feelings. First, the aged farmer is expected to prefer and use CP (especially, minimum tillage) because minimum tillage is less laborious and less time consuming but the findings revealed otherwise.

Second, the observed less preference and use of CP (in this case, land fallow technique) could be because aged people find it difficult to move from one fallow land to another and as such opt for another SWC practices. The inverse and significant relationship of the gender of farmer and government institutional support with CP 
could be said to have the same explanation as in the case of SAP. In the same vein, the findings also revealed that the preference and use of AP in the study area is significantly determined by age $(p<0.01)$, gender $(p<0.05)$, membership of local level institutions $(p<0.01)$ and farmers' perception on the impact of extension visit $(p<0.1)$. Age and gender of the farmers negatively influence the preference and use of AP in the study area; as such, the same explanation could be attributed as in the case of CP. Also, membership of local level institutions and farmers' perception of the impact of extension visit do have an inverse influence on the preference and use of AP. This suggests that being a member of any social organization does not have any positive influence on the preference and use of SWC practices especially AP.

Furthermore, it means that farmers in these local level institutions mostly focus on credit facilities and social activities instead of sharing useful information also that can be beneficial and assist members in mitigating the prevalent land/soil and water challenges in agricultural production. In the case of farmers' perception of the impact of extension visit, the same explanation could be given for this also as in the case of SAP. These findings are consistent with Miller, Chin and Zook, (2012) who submitted that education is required to answer why questions, given that, farmers who are knowledgeable about the environmental, agronomic, and economic benefits of SWC practices are more likely to adopt them. Also, in line with Druschke and Secchi, (2014), gender exercises a nuanced, critical, and understudied influence on farmers' choice and use of SWC practices; a plausible explanation for this is that, female farmers usually have significantly more positive attitudes toward conservation practices and collaboration than the male counterparts.

Meanwhile, younger farmers according to Gabrielyan, Chintawar and Westra, (2010) are also likely to adopt alternative tillage and SWC practices at higher rates than the older ones. Perhaps because they have longer farming horizons and can benefit more from long-term conservation benefits, or because they are more environmentally oriented, and maybe because older farmers are more set in their obsolete ways and embedded in old and longstanding community traditions of the right way to farm. All in all, it could be inferred from the results of the fitted logit regression models that age, gender, years of formal education, membership of local level institutions (that is, social organizations and community based organizations), access to extension services and frequency of extension visit as well as farmers' perception on the impact of extension visit are significant influencing dynamics governing the rural farmers' preference and use of SWC practices alternatives in the study area.

Table 4: Factors influencing the preference for SWC practices alternatives

\begin{tabular}{lccc}
\hline CA adoption decision & SAP & CP & AP \\
\hline Age & $-0.0005(-0.19)$ & $-0.0069(-2.16)^{* *}$ & $-0.0139(-4.17)^{*}$ \\
Gender & $-0.2350(-2.88)^{*}$ & $-0.2794(-3.96)^{*}$ & $-0.2122(-2.39)^{* *}$ \\
Years of formal education & $-0.0146(-1.82)^{* * *}$ & $-0.0047(-0.51)$ & $0.0006(0.06)$ \\
Household size & $-0.0014(-0.08)$ & $-0.0013(-0.07)$ & $0.0213(1.10)$ \\
Farm size under cultivation & $-0.0016(-0.05)$ & $-0.0039(-0.12)$ & $0.0439(1.33)$ \\
Membership of local level institutions & $0.0613(0.81)$ & $-0.0577(-0.61)$ & $-0.2787(-2.66)^{*}$ \\
Access to extension services & $-0.5116(-3.75)^{*}$ & $-0.7891(-2.11)^{* *}$ & $0.0014(0.01)$ \\
Frequency of extension visit & $0.1279(2.60)^{*}$ & $0.0492(0.84)$ & $-0.0276(-0.46)$ \\
Perceived impact of extension visit & $0.1826(2.22)^{* *}$ & $0.1012(1.24)$ & $-0.1404(-1.84)^{* * *}$ \\
Mode of land acquisition & $0.0199(0.31)$ & $-0.0034(-0.04)$ & $0.0203(0.27)$ \\
\hline
\end{tabular}

Figures in parenthesis are z-values of the coefficients; Number of observation $=221$

$*, * *$ and ${ }^{* * *}$ - represent $\mathrm{p}<0.01, \mathrm{p}<0.05$ and $\mathrm{p}<0.1$ probability levels respectively.

Source: Data Analysis, 2017

Estimating Differences of Proportions: To further ascertain the appropriateness and reliability of the fitted model, McNemar's diagnostic test was applied to estimate differences of proportions with respect to the binary response variable(s). McNemar's test is analogous to the paired t-test, except that it is applied only to dichotomous data especially when it has to do with binary response variable(s). In comparing the means in 
two or more groups of paired observations, the standard t-tests are not always appropriate because the variance of the difference in means is derived under the assumptions that the two groups are independent and so it does not take into account the covariance-correlation term which can either increase or decrease that term. However, the resultant effect in this scenario is that both the hypothesis tests and confidence intervals that are based on this assumption will not provide the accurate inference. To correct these anomalies, McNemar's diagnostic test for paired binomial data is applied. The benefit of conducting the diagnostic tests is that, it is always necessary to separate the true positive cases and the true negative cases as determined by reference standard information and analyze them separately. Therefore, McNemar's test is an approximate test to provide an accurate and valid picture of the fitted logit regression model.

McNemar's Diagnostic Tests: The findings from the tests conducted were shown in Tables $5 \mathrm{a}, 5 \mathrm{~b}$ and $5 \mathrm{c}$ respectively. The findings from Table 5a (SAP and CP) revealed a relative difference of 0.5546875 which suggests that for every 100 controls (i.e. those not using any SWC practices), 55.4\% might be expected to use any of these SWC practices if they chose to be exposed to and easily access modern SWC training. Also, it appears the sensitivity of the tests results is different by about $32 \%$ as observed from the result. The same explanation holds for the relative differences of 0.278481 in Table $5 \mathrm{~b}$ (SAP and AP) while its sensitivity of the tests result is different by approximately $10 \%$. On the other hand, as in the case of Table 5c (CP and AP), the findings revealed a relative difference of -0.6202532and it appears that the tests differ slightly with respect to specificity, although the difference is inverse and likely uninteresting. The idea of the odds ratio for matched pairs is the odds of using any SWC practices given that the farmer is exposed to modern SWC training relative to the odds of using SWC practices when not exposed to modern SWC training.. The odds ratio of 6.07 as shown in Table 5a suggests that a farmer is nearly 6 times more likely to use any SWC practices if such is exposed to modern SWC training than if otherwise. The same explanations hold for Tables $5 \mathrm{~b}$ and $5 \mathrm{c}$ with an odds ratio of 1.55 and 0.19 respectively. In other words, the odds ratio tells us the strength of the relationship or association. The odds ratio in Table $5 \mathrm{c}$ is not unexpected because of the inverse nature of its relative difference value earlier reported. In the same vein, the Exact McNemar significance probability values (p-values) as in the case of Tables $5 \mathrm{a}, 5 \mathrm{~b}$ and $5 \mathrm{c}$ were estimated at $p<0.01, p<0.05$ and $p<0.1$ respectively. Suffix to say that, the size of p-values tells us how certain we are that the proportion of cases using SWC practices are different from the proportion of controls.

Table 5a: Testing for SAP and CP

\begin{tabular}{|c|c|c|c|}
\hline \multirow[b]{2}{*}{ Cases } & \multicolumn{2}{|c|}{ Controls } & \multirow[b]{2}{*}{ Total } \\
\hline & Exposed & Unexposed & \\
\hline Exposed & 79 & 85 & 164 \\
\hline Unexposed & 14 & 43 & 57 \\
\hline Total & 93 & 128 & 221 \\
\hline
\end{tabular}

McNemar's chi ${ }^{2}(1)=50.92 \quad$ Prob $>\operatorname{chi}^{2}=0.0000$

Exact McNemar significance probability $\quad=0.0000$

Proportion with factor

\begin{tabular}{|c|c|c|c|}
\hline Cases & 0.7420814 & & \\
\hline Controls & 0.4208145 & [95\% Conf. & nterval] \\
\hline difference & 0.321267 & 0.2393307 & 0.4032033 \\
\hline ratio & 1.763441 & 1.505853 & 2.065091 \\
\hline rel. diff. & 0.5546875 & 0.4530186 & 0.6563564 \\
\hline odds ratio & 6.071429 & 3.427256 & 11.57484 \\
\hline
\end{tabular}


Table 5b: Testing for SAP and AP

\begin{tabular}{lccc}
\hline \multirow{2}{*}{ Cases } & \multicolumn{2}{c}{ Controls } & Total \\
\hline Exposed & Exposed & Unexposed & 164 \\
Unexposed & 102 & 62 & 57 \\
Total & 40 & 17 & 221 \\
\hline
\end{tabular}

McNemar's chi' ${ }^{2}(1)=4.75 \quad$ Prob $>\operatorname{chi}^{2}=0.0294$

Exact McNemar significance probability $=0.0371$

Proportion with factor

$\begin{array}{llll}\text { Cases } & 0.7420814 & & \\ \text { Controls } & 0.6425339 & {[95 \% \text { Conf. Interval] }} \\ & -1.0 .-19 & \\ \text { difference } & 0.0995475 & 0.0064208 & 0.1926742 \\ \text { ratio } & 1.15493 & 1.01443 & 1.314889 \\ \text { rel. diff. } & 0.278481 & 0.0656451 & 0.491317 \\ \text { odds ratio } & 1.55 & 1.025109 & 2.367606 \quad \text { (exact) }\end{array}$

Table 5c: Testing for $\mathrm{CP}$ and AP

\begin{tabular}{|c|c|c|c|}
\hline \multirow[b]{2}{*}{ Cases } & \multicolumn{2}{|c|}{ Controls } & \multirow[b]{2}{*}{ Total } \\
\hline & Exposed & Unexposed & \\
\hline Exposed & 81 & 12 & 93 \\
\hline Unexposed & 61 & 67 & 128 \\
\hline Total & 142 & 79 & 221 \\
\hline
\end{tabular}

McNemar's chi ${ }^{2}(1)=32.89 \quad{\text { Prob }>\operatorname{chi}^{2}=0.0000}^{2}$

Exact McNemar significance probability $\quad=0.0000$

Proportion with factor

\begin{tabular}{|c|c|c|c|}
\hline Cases & 0.4208145 & & \\
\hline Controls & 0.6425339 & [95\% Conf. Ir & terval] \\
\hline difference & -0.2217195 & -0.2961523 & -0.1472866 \\
\hline ratio & 0.6549296 & 0.56612 & 0.757671 \\
\hline rel. diff. & -0.6202532 & -0.890073 & -0.3504333 \\
\hline odds ratio & 0.1967213 & 0.096407 & 0.3690071 \\
\hline
\end{tabular}

\section{Conclusion and Recommendations}

The study concludes that Agronomic Practices (AP) is the most preferred and used SWC practice options in the study area as evident from the cross-tabulation and MCDM results. Also, the findings revealed that age, gender, years of formal education, membership of local level institutions (that is, social organizations and community based organizations), access to government support (extension delivery services) and number of contact with extension agents as well as farmers' perception on the impact of extension visit are significant influencing dynamics governing the smallholder farmers' preference and use of SWC practices alternatives in the study area. Consequent on the findings of this study, the following recommendations are of importance: There is a need for active participation in farming operation within the ambient of production capacity of individuals as ageing sets in; this is evident from the findings of this study. Similarly, adult education should be promoted with the existing Universal Basic Education (UBE) system to ensure a quality education that can aid uptake of modern farming techniques among aged people since it was evident that the use of SWC declines with age increase. More so, active sensitization is necessary on the need for people to embrace farming regardless of individual's educational attainment; this is paramount because human capital (proxied by years of formal education) inversely and significantly affects the preference and use of SWC practices. 
In fact, active farming participation especially speaks directly to youths (female gender inclusive) who migrate to look for white collar jobs in the cities after a certain level of educational attainment. Thus, the need for their active involvement in farming activities as well as the readiness to use new innovations that can boost food production cannot be underestimated. Hence, agricultural policy should not be gender bias and as such, female gender roles should go beyond being relegated to households' chores. Additionally, extension service delivery is an important gateway to disseminate agricultural innovations to farmers especially when it has to do with pathways addressing the effects of soil/land degradation and water conservation; therefore, efforts need to be geared up on the frequency of visits by extension agents, services rendered, farmers' training as well and capacity building programme for smallholder farmers on the need for modern soil/land and water conservation practices in a bid to ensure food and nutrition security in line with the sustainable development goals. Also, there is a need to encourage investment in local level institutions among smallholder farmers because membership of local level institution was found to have inverse effects on the preference and likelihood use of SWC practices by farmers. The local level institution is regarded as a strong tie which facilitates mutual interactions among heterogeneous network members; this could further be achieved through effective intra and interlocal institutional framework where relevant and useful information can be acquired as well as diffusion of beneficial ideas could be ensured especially in the aspects of improved farming techniques.

\section{References}

Adimassu, Z., Gorfu, B., Nigussie, D., Mowo, J. \& Hilemichael, K. (2013). Farmers' Preference for Soil and Water Conservation Practices in Central Highlands of Ethiopia. African Crop Science Journal, 21(3), 781-790.

Amemiya, A. (1981). Qualitative response models: A survey. Journal of Economic Literature, 19, 1483-1533.

Ananda, J. \& Herath, G. (2009). A critical review of multi-criteria decision-making methods with special reference to forest management and planning, Ecological Economics, 68, 2535-2548.

Anande-Kur, S. (1986). Control and management of erosion. The Agulu-Nanka gully erosion scheme (case study). Paper presented at the National Workshop on soil erosion held at the Federal University of Technology, Owerri Imo State, Nigeria.

Babalola, D. A. \& Olayemi, J. K. (2013). Determinants of Farmers' Preference for Sustainable Land Management Practices for Maize and Cassava Production in Ogun State, Nigeria. Being an invited paper presented at the $4^{\text {th }}$ International Conference of the African Association of Agricultural Economists (AAAE), 22-25.

Bravo-Ureta, B., Solis, D., Cockhi, H. \& Omroga, R. (2006). The impact of soil conservation and output diversification on farm income in Central American hillsides farming. Agricultural Economics, 35, 267-276.

Chaudhuri, A. (2014). Solving Real Life Multi-Criteria Decision Making Problems using Criteria Analysis Technique.

Dimelu, M. U., Ogbonna, S. E. \& Enwelu, I. A. (2013). Soil conservation practices among Arable Crop Farmers in Enugu-North Agricultural Zone, Nigeria: Implications for Climate Change. Journal of Agricultural Extension, 17(1), 1-13.

Druschke, C. G. \& Secchi, S. (2014). The Impact of Gender on Agricultural Conservation Knowledge and Attitudes in an Iowa Watershed. Journal of Soil and Water Conservation, 69(2), 95-106.

Dumanski, J., Peiretti, J., Benitis, R., McGary, D. \& Pieri, C. (2006). The Paradigm of Conservation Tillage. Proceedings of World Association of Soil and Water Conservation, 58-64.

Ezeaku, P. I. (2012). Soil conservation and management options for adaptation to climate change in the 21st century in: Enete, A.I. and Uguru, M.I. (eds) Critical Issues in Agricultural Adaptation to Climate Change in Nigeria, Enugu, Chengo Limited, 84-113.

Gabrielyan, G., Chintawar, S. \& Westra, J. (2010). Adoption of cover crops and its effect on nitrogen use by farmers. Paper presented at the annual meeting for the Southern Agricultural Economics Association, Orlando, FL, 6-9.

Gujarati, D. N. (1988). Basic Econometrics. 2nd edition. New York: McGraw-Hill, 98-102.

Hajkowicz, S. (2008). Rethinking the Economists evaluation toolkit in light of sustainability policy. Sustainability: Science, practice and policy, 4(1), 17-24.

Hajkowicz, S. \& Collins, K. (2007). A Review of Multiple Criteria Analysis for Water Resource Planning and Management, 21, 1553-1566. 
Herva, M. \& Roca, E. (2013). Review of combined approaches and multi-criteria analysis for corporate environmental evaluation. Journal of Cleaner Production, 39, 355-371.

Howard, A. (1991). A critical look at multiple criteria decision-making techniques with reference to forestry applications. Canadian Journal of Forest Research, 21(4), 1649-1659.

Iheke, O. R. \& Onyenorah, C. O. (2012). Awareness, preferences and adoption of soil conservation practices among farmers in Ohafia Agricultural Zone of Abia State, Nigeria. Journal of Sustainable Agriculture and the Environment, 13(1), 1-8.

James, P. H. \& Ngala, A. L. (2015a). Farmers' Awareness, Preference and Adoption of Soil Conservation Practices in Zing Local Government Area of Taraba State, Nigeria. Journal of Biology, Agriculture and Healthcare, 5(11), 1-5.

James, P. H. \& Ngala, A. L. (2015b). Survey on Soil Conservation Practices among Food Crop Farmers in Zing Local Government Area of Taraba State, Nigeria. International Journal of Plant \& Soil Science (SCIENCEDOMAIN International), 8(3), 1-7.

Jansen, H. G. P., Damon, A., Rodriguez, A., Pender, J. \& Schipper, R. (2006). Determinants of income-earning strategies and sustainable land use practices in hillside communities in Honduras. Agricultural system, 88(1), 92-110.

Mbagwu, J. S. C. (2003). Aggregate stability and soil degradation in the tropics. Lecture delivered at the College of Soil Physics, Trieste, Italy. 2003.

Mendoza, G. A. \& Martins, H. (2006). Multi-criteria decision analysis in natural resource management: A critical review of methods and new modelling paradigms. Forest Ecology and Management, 230, 1-22.

Miller, L., Chin, J. \& Zook, K. (2012). Policy opportunities to increase cover crop adoption on North Carolina farms. Masters project, Duke University.

Olatunji, O. J. (2003). The effect of socio-characteristic of farmers on land degradation in the derived GuineaSavannah Ecological Zone of Nigeria. International Journal of Environmental Issues, 1(1), 237-241.

Olawuyi, S. O. \& Balogun, T. A. (2017). The Endogeneity Effects of Conservation Agriculture Adoption on Smallholder Farmers' Food Security Status in Osun State, Nigeria. Journal of Economics and Behavioral Studies, 9(5), 144-156.

Saaty, T. (1987). The Analytic Hierarchy Process: What it is and how it is used. Mathematical Modelling, 9(35), 161-176.

Salako, F. K. \& Tian, G. (2003). Soil water depletion under various leguminous cover crops in the derived savannah of West Africa. Agriculture, Ecosystems and Environment, 100(2\&3), 173-180.

Smith, B. \& Smithers, J. (2006). Adoption of Soil Conservation Practices: An empirical analysis in Ontario, Canada. Land Degradation and Rehabilitation, 3, 1-14.

Toda, T., Amano, K., Abe, H. \& Nakagawa, D. (1981). Stepwise Evaluation Method Based on Multi-Criteria Analysis. IFAC Control Science and Technology, (8th Triennial World Congress) Tokyo, Japan, 15071512 . 